\title{
Applying a Modified Technology Acceptance Model to Qualitatively Analyse the Factors Affecting E-Portfolio Implementation for Student Teachers' in Field Experience Placements
}

\author{
Eugenia M. W. Ng, Ronnie H. Shroff, and Cher Ping Lim \\ The Hong Kong Institute of Education, Hong Kong, China
}

\author{
eugenia@ied.edu.hk, rshroff@hkbu.edu.hk, clim@ied.edu.hk
}

\begin{abstract}
The study involved student teachers enrolled in the Bachelor of Education English Language Programme at the Hong Kong Institute of Education. Students $(N=77)$ participated in a pilot study by electronically submitting their field experience portfolios in their third and fourth year of study. Student teachers were invited through e-mails to participate in focus group interviews. The purpose of this interview was to examine the merits and challenges of digitising the existing FE paper-based portfolio, using a digital portfolio platform, and to plan for future development using Technology Acceptance Model (TAM) as the research framework. All participants were required to create e-portfolios to showcase their achievements, the effects of actual system used led to long-term behavioural intention to use, diverging from the TAM's original model, which predicted actual system use. Student teachers either participated in a semi-structured interview $(n=7)$ or replied via e-mails $(n=2)$. The results indicated that attitude towards usage (ATU) evidenced a direct relationship to behavioural intention to use. Furthermore, for those who had mixed ATU, perceived usage was the determining factor. The findings provide insightful information not only for the next implementation phase of an e-portfolio, but also for those considering implementing e-portfolios.
\end{abstract}

Keywords: e-portfolio, field experience, student teacher, qualitative analysis, Technology Acceptance Model

\section{Introduction}

Portfolios have long served as a vehicle for students to showcase achievements that could not be appropriately presented in written form, such as for art or architecture disciplines. Recently, information technology (IT) has provided tools for portfolios to be stored, accessed, updated, and presented conveniently as evidence of student learning and achievement (Chau \& Cheng, 2010; Gaide, 2006). Although there is no generally agreed upon definition of electronic portfolios (e-

Material published as part of this publication, either on-line or in print, is copyrighted by the Informing Science Institute. Permission to make digital or paper copy of part or all of these works for personal or classroom use is granted without fee provided that the copies are not made or distributed for profit or commercial advantage AND that copies 1) bear this notice in full and 2) give the full citation on the first page. It is permissible to abstract these works so long as credit is given. To copy in all other cases or to republish or to post on a server or to redistribute to lists requires specific permission and payment of a fee. Contact Publisher@InformingScience.org to request redistribution permission.
Portfolios; Hallam \& Creagh, 2010), an

e-portfolio usually comprises a selection of specific artefacts to showcase students' learning processes, outcomes, and reflections (Gaide, 2006). The internet, providing an added benefit of portability, affords the opportunity to make learning visible, to present a wide range of student achievements apart from academic attainments (Abrami \& Barret, 2005 ), and to satisfy programme re- 
quirements for those seeking employment (Strudler \& Wetzel, 2008). When creating e-portfolios, student teachers have become more capable technically had had better disposition towards adopting technology for creating and maintaining portfolios (Herner-Patnode and Lee, 2009, Thang, Lee \& Zulkifli, 2012). Similarly, English teachers found that creating e-portfolio enabled them to develop their professional and information technology competencies (Bala, Mansor, Stapa \& Zhkaria, 2012) whilst student teachers regarded the e-portfolio platform easy to use and gave them a sense of editorship and promote discussion (Chuang, 2010).

Apart from technical advantages, the implementation of e-portfolios promotes efficacious pedagogical practices (e.g., reflective thinking; Orland-Barak, 2005). Goldsby and Fazal (2000) observed that student teachers who created e-portfolios were not only more likely to use technology in their teaching, but were also more effective at creating meaningful learning experiences for their pupils using technology. Students feel more confident and positive towards their learning when using e-portfolios (Hussein, 2009; Shroff, Deneen \& Ng, 2011; Wright, Stallworth, \& Ray, 2002; Zhang, Olfman, \& Ractham, 2007). E-portfolios are also used as a resource for helping preservice teachers not only document their work towards meeting professional standards, but also reflect on their teaching practices (Abrami \& Barret, 2005; Ayala, 2006, Chuang, 2008, Sung, Chang, Yu \& Chang, 2008), in particular, reflection-of-practice and reflection-on-practice (Makinster, Barab, Harwood, \& Anderson, 2006). However, there are also problems when creating e-portfolios, e.g., required computer and internet access, and lost personal time spent on assisting those with technical problems when unfamiliar systems are used (Shepherd \& Hannafin, 2011), and were frustrated whilst formatting and sharing portfolios (Shepherd \& Bolliger, 2011). Implementing e-portfolios is very costly. Moreover, they directly compete with new communication technologies, e.g., mobile phones; (Evans \& Schwen, 2006) that students are comfortable with (Evans \& Powell, 2007).

\section{The Research Framework}

User-friendliness and user acceptance of e-portfolio systems are two integral elements for successful implementation, as users would become frustrated and simply abandon a confusing system (Jafari, 2004). The Technology Acceptance Model (TAM) seems to be an appropriate model for understanding conceptual issues related to e-portfolio use. It suggests that the success of a system can be determined by user acceptance, measured by three factors: perceived usefulness (PU), perceived ease-of-use (PEOU), and attitudes towards usage (ATU) of the system (Davis, 1989). A number of external variables could affect PU and PEOU. PU is the degree to which a person believes that using a particular system would enhance his or her performance whilst PEOU refers to the degree to which a person believes that he or she could use the particular system without effort. PU and PEOU can be considered cognitive factors, whereas ATU represents individuals' evaluative feelings (positive or negative) when performing a particular behaviour (Ajzen \& Fishbein, 2000). It has been identified as a factor that guides future behaviour and as an intentional cause that ultimately leads to a particular behaviour. According to the model, a user's perceptions of a system's usefulness and ease-of-use result in a behavioural intention to use (BIU), or not to use, the system (Davis, Bagozzi, \& Warshaw, 1989; Nov \& Ye, 2008). TAM has received empirical support for robustly predicting technology adoption in various contexts and with a variety of technologies (Gao, 2005; McKinnon \& Igonor, 2008; Park, 2009; Sugar, Crawley, \& Fine, 2004; Teo, 2009). Yet, these prior studies mainly examined different factors by quantitatively analysing collected questionnaires. In contrast, we adopted TAM as a research framework to qualitatively examine different factors that affect the implementation of e-portfolios. Since all participants created an e-portfolio to showcase their achievements, the effects of actual system used led to long-term BIU, diverging from TAM's original model, which predicted actual system use (Davis, 1989). Figure 1 shows how actual system use affects BIU, instead of the converse. 


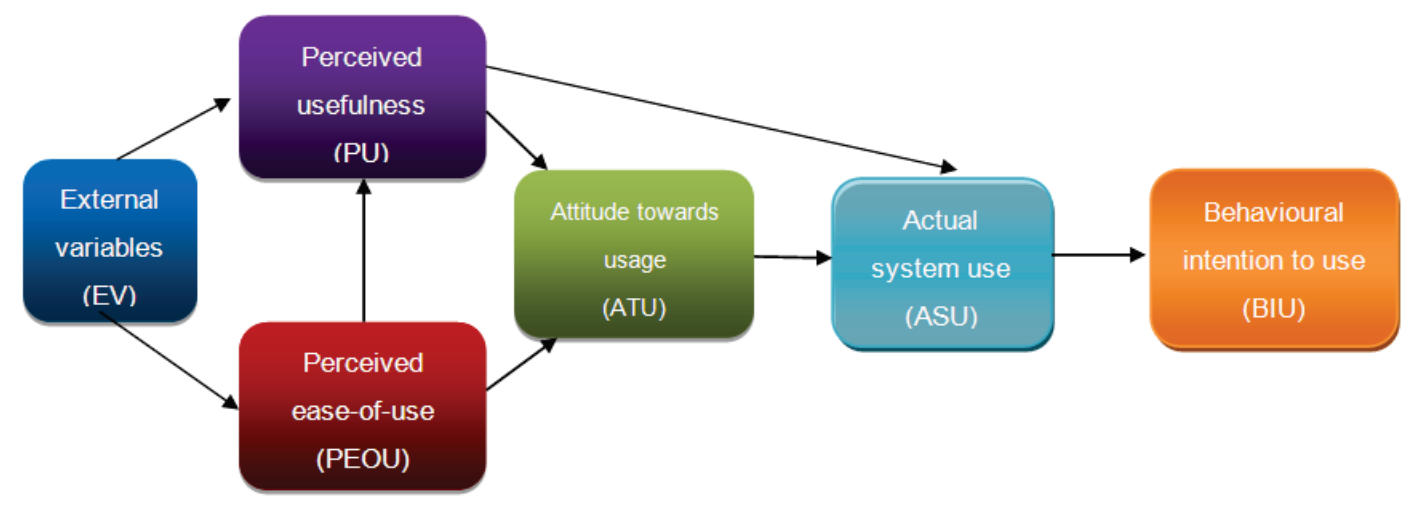

Figure 1. The research framework: A modified technology acceptance model.

\section{The Study}

\section{Participants}

The current study was conducted at the Hong Kong Institute of Education (HKIEd), the sole teacher education institute in Hong Kong (though some universities have education faculties). It involved all student teachers enrolled in the Bachelor of Education English Language Programme who were enrolled in 1998/1999. The student teachers used a dedicated e-portfolio platform (i.e., Mahara) to demonstrate the advancement and development of their competencies/skills, individual and collaborative growth, achievement, and learning during the field experience (FE). The eportfolio pilot commenced in the Spring of 2011, during students' FE that occurred in their third year of study. They participated again in Autumn 2011, when they were in their fourth year of study. They attended a compulsory training session on how to create e-portfolio using Mahara prior to their FE. Template, supporting documents and technical support were also provided for both years.

\section{Tasks}

The FE is an important learning experience that provides student teachers with the opportunity to apply learning theories to teach a subject in an authentic classroom. Student teachers were supported by teachers in their FE schools and by their supervisors at HKIEd, who assessed them through lesson observations. Apart from teaching, student teachers are required to submit a portfolio providing evidence of their teaching performance. The portfolio included 1) lesson plans, 2) teaching resources (e.g., teaching materials and worksheets for every lesson), 3) a reflection after each lesson, and 4) an overall reflection for the FE (see Figure 2). The portfolios provided another perspective concerning the student teachers' teaching competencies and were assessed by supporting teachers. All student teachers had to submit paper-based portfolios at the end of their FE but the participants had to submit their portfolios at the Mahara platform. Therefore, the purpose of this pilot study was to examine the merits and challenges of digitising the existing FE paperbased portfolio, using a digital portfolio platform, and to plan for future development. 


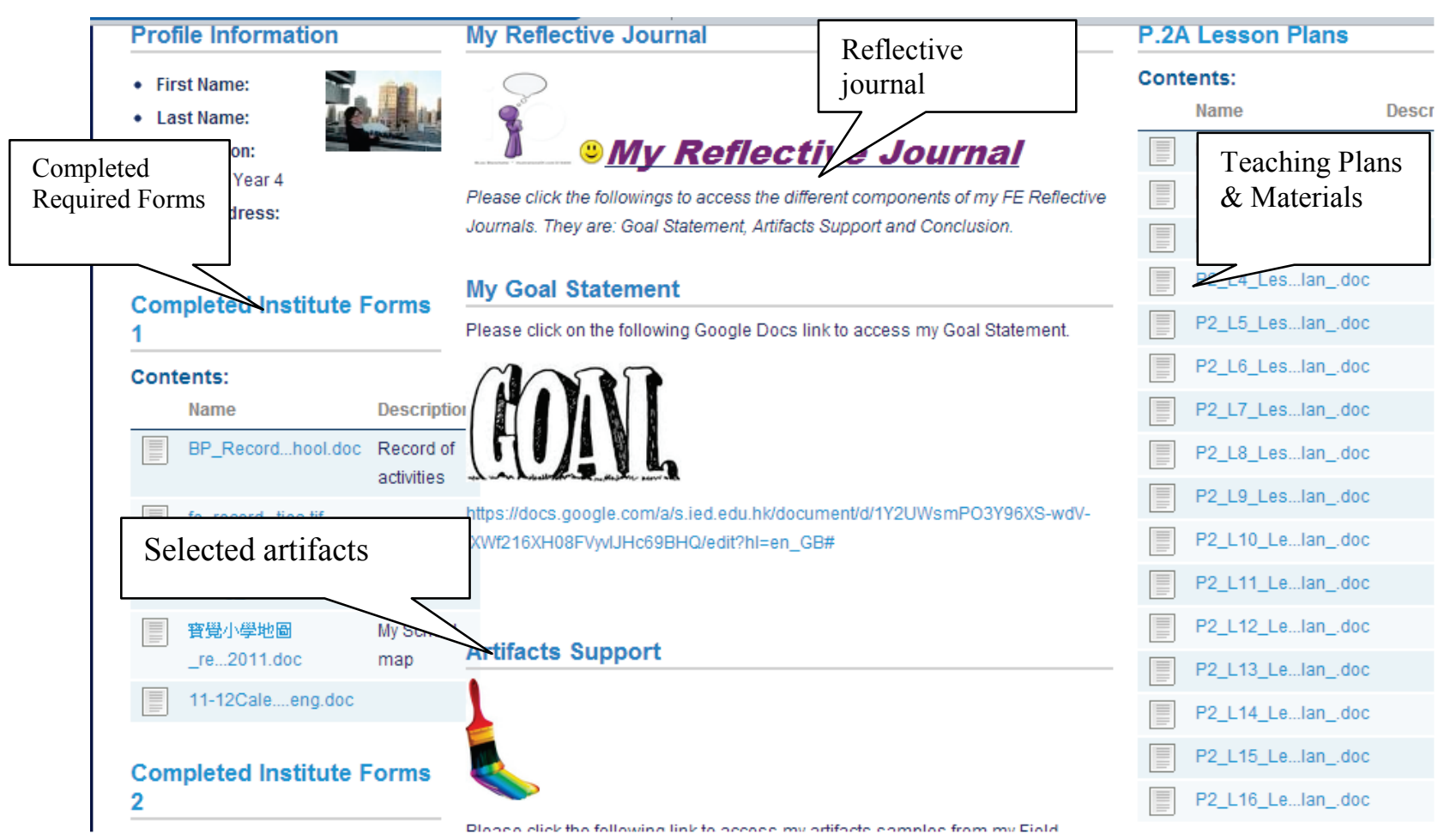

Figure 2. Sample of a field experience portfolio.

\section{Data Collection}

Participants were invited by e-mail to take part in a semi-structured interview in the Spring of 2012 in order to obtain their views on constructing e-portfolios using the Mahara digital portfolio platform. Volunteer student teachers individually attended semi-structured interviews $(n=7)$ or responded via e-mail $(n=2)$. The interviews were conducted by the first author with the assistance of a research assistance who recorded the interviews. The interview questions were related to the factors of modified TAM framework as shown in Figure 1. The research assistance then transcribed the interviews and sent back to the interviewees for confirmation. A majority of participants were female $(n=7)$, reflecting the high percentage of female students enrolled in the programme.

\section{Findings and Discussion}

\section{External Variables}

There could be a number of pertinent external variables, but the most important one in the current pilot study was training. All participants attended the training sessions and all of them found them useful. Comments from students are quoted below.

Yes, it definitely helps a lot, as it provides clear explanations and instructions on using the system in order to facilitate our skills in developing and organising our portfolio. (Student A)

Yes, it was useful. It helped me understand how to use it. But it doesn't mean it made it any easier or that the platform was any more user-friendly. (Student C) 
The training was very comprehensive and delivered by the same person who gave comprehensive guidelines. I think this helped. When I tried to upload some documents to Mahara, I could follow the guidelines and was able to handle the documents by myself. (Student E)

Although participants did not encounter any problems in the workshops, some encountered difficulties when using the Mahara e-portfolio platform when they uploaded artefacts Therefore, they would have preferred to have the training session on uploading artefacts after the session on teaching practices.

The instructor demonstrated how to use it and we tried using it during the workshop. However, they didn't take into account how we used Mahara during the field experience. Because we did it before the field experience or after the field experience, we didn't have much time to look at the guidelines again. Then we forgot how to actually use it. (Student G)

\section{Perceived Ease of Use (PEOU)}

All participants found the Mahara platform too difficult to use, despite the fact that they had attended training workshops. The user interface was very different from that of other familiar platforms and the names of the features were very confusing. Furthermore, the Mahara platform was rather restrictive, preventing the upload of animations or other types of sophisticated content.

Negative comments:

The interface and use of Mahara are totally new things compared to other tools we are familiar with (e.g., e-mail). Even when I used Mahara for the second time, I had to find the menu and read it again to find out how to send the link to my supervisor. (Student B)

Make it simple.... The names of the tools were so confusing that I had the materials in the wrong place and I had to do it all over again. (Student F)

I think this is very complicated.... When I wanted to change the configuration of the page and the names of some subtitles, I found out that I couldn't change the names after I opened it to the public because you have different papers or pages there. I tried to open one, but I found that I couldn't change the name. Then I had to remove the whole part of the document and do it again. (Student G)

However, no participants requested extra training, as they believed any platform should be easy enough to use without training.

If an e-portfolio requires such training, it has already defeated the purpose: it should be understandable without an hour of step-by-step training and manuals. (Student C)

\section{Perceived Usefulness (PU)}

The e-portfolio was meant to help participants showcase their FE learning journey and to reflect. Most students felt that Mahara helped them keep a record of the different files that they created during the FE, but only four students believed that creating an e-portfolio helped them reflect, with three additional participants disagreeing, and two remaining indifferent to the issue.

Positive comments:

I have made use of providing and receiving feedback on the platform. It is an effective way to provide and receive feedback, as prompt and simultaneous feedback can generate facilitative learning. (Student A)

It showed the whole process of your field experience. When you reflected, you could refer back to the files you uploaded or the pictures that reminded you "that's the exact lesson I taught". From those data and forms of evidence, I could think of examples when writing the reflection. (Student F) 
I think it is a good tool for me to reflect on my field experience. Now, I don't really remember the details about my e-portfolio, but when I login and check it, I find that the documents are clearly shown there. I feel very pleased to see my development during the field experience process. (Student I)

No strong feelings:

I think Mahara is just a platform for me to upload materials. I need to do the reflections and I just did the reflections. I typed and handed in the soft copy as the hard copy, so it didn't affect my reflections. (Student E)

Negative comments:

Not at all. I did my reflections without the e-portfolio. I did my reflections every day. I mean I didn't type it. (Student H)

\section{Attitude towards Usage (ATU)}

When participants were asked to compare using paper-based portfolios and e-portfolios, they thought the main advantages of e-portfolios were their environmental friendliness. Some of them thought that e-portfolios were convenient and more organised, but only one student used them to communicate. Many of them were unhappy that they had to participate in the pilot study using an unfamiliar platform. The situation was well understood, as none of them regarded themselves as very IT savvy. Regarding feelings about using Mahara for creating e-portfolios, one participant had positive feelings, four expressed mixed feelings, three expressed negative feelings, and one was indifferent.

Positive feelings:

I think it is better than the paper-based portfolio because when I uploaded those teaching materials, I could see them at the same time via the platform. It was a better way for me to organise, just like the icon on the window. (Student E)

Mixed feelings:

I think it helps to some extent. Like the videos of my teaching, I think paper-based portfolios cannot show what I have. E-portfolios can because you can upload the video or PowerPoint with animations or something like that. So I think it is 50/50. I personally prefer the paper-based portfolio more because sometimes you cannot access the internet depending on where you are. However, the paper-based portfolio lets you carry a lot of materials anywhere. (Student G)

I am supportive of one thing concerning the use of Mahara: it is really environmentally friendly.... So it won't waste that much paper compared to others. That's one advantage, despite its lack of user-friendliness. (Student $\mathrm{H}$ )

Negative feelings:

So maybe the institute should decide which e-platform they are going to use and stick with it. Don't provide too many. The timing is very important. Don't introduce things in the middle, as people won't accept it. It is not about Mahara itself; it is about the policy and the administrative procedure. (Student B).

It could start being used from the first year for students to keep their own study records (e.g., assignments, presentations, or even the documents they download from Blackboard). (Student $\mathrm{H}$ )

\section{Actual System use (ASU)}

To further investigate if participants complied with the initiative, we examined their e-portfolios. All participants, with one exception, created a well-organised e-portfolio using the Mahara platform. Concerning the exception, that student most likely inadvertently deleted it rather than failed 
to make one, as all participants were required to maintain e-portfolios. Thus, the requirement made a large difference to actual system use, despite negative levels of PEOU and PU.

\section{Users' Behavioural Intention to Use (BIU) the System}

E-portfolios supposedly cater to different purposes. One notable example of a longer BIU is fourth-year students using an e-portfolio to aid their employment-seeking efforts. Table 1 shows that ATU had a direct relationship to BIU, as those who had evidenced a positive ATU intended to use the system, and vice versa. For the four participants who evidenced mixed ATU, two intended to use e-portfolios to showcase their achievements during job interviews (or to anyone who might be interested in them), one did not intend to use it, and one still had mixing feelings because she would need to make it more attractive prior to showcasing it to potential employers. It seems that PU was the determining factor that led to those mixed feelings of ATU to intend to use the system, as the two participants who had positive PU intended to use the system, whereas the participant who demonstrated a negative level of PU did not intend to use it. The student who had mixed feelings of ATU and BIU appeared to be rather indecisive, even though she evidenced positive levels of PU.

Table 1 Students' Responses

\begin{tabular}{|l|l|l|l|l|l|l|l|}
\hline Student & EV & PEOU & PU & ATU & ASU & BIU \\
\hline & & & Organisation & Reflection & & & \\
\hline A & Y & Y & Y & N/A & N/A & Y & N/A \\
\hline B & Y & Y & Y & N/A & N & N/A & N \\
\hline C & Y & Y & N & N & N & Y & N \\
\hline D & Y & Y & Y & Y & Y/N & Y & Y \\
\hline E & Y & Y & Y & N & Y & Y & Y \\
\hline F & Y & Y & Y & Y & Y/N & Y & Y \\
\hline G & Y & Y & Y & Y/N & N & Y & N \\
\hline H & Y & Y & N & N & Y/N & Y & N \\
\hline I & Y & Y & Y & Y & Y/N & Y & Y/N \\
\hline
\end{tabular}

Note. N/A indicates students who did not answer the question directly.

Comments from students are quoted below.

We established different folders and showed pictures and videos. I think that was the most interesting and helpful thing. I have uploaded some pictures. Because the pictures can give anyone who visits this website a very direct and visual image, and help him/her get the main ideas of what I have been doing. (Student F)

It provided a clear framework of elements that you could put in your portfolio. It is a good way for us to think what we can showcase. ... I have some schoolmates who are now in-service teachers who have a large pile of portfolios to send to every job application. This is not effective and efficient, and when schools look at that pile of materials, they will be shocked. E-portfolios are a way to show that we have technological competencies, which are very important nowadays. (Student D)

Those participants who did not intend to use e-portfolios further believed that they would prefer other means of technology that were simple, such as Facebook, e-mail, and/or mobile phones 
(Evans \& Schwen, 2006). The findings suggested that PEOU affects students' BIU of the eportfolio system, despite positive levels of PU and ATU. Those who spent more time creating eportfolios appeared to be likely to use the system, whereas those who encountered some technical difficulties seemed unlikely to use the system. Comments from students are quoted below.

No. We use mobile phones besides computers to contact classmates. It is much easier and more direct. One more thing is that they don't often check Mahara. ... Basically we like the idea of using Mahara, because it looks very professional for the education sector. However, if you have really used it then you find out it is not practical.... But nobody used Mahara; no one knew how to use it. We know that there is a check box or message box there, but after we added everyone, we never used it. We didn't use Mahara because of other resources like Google or other similar software programs. (Student G)

If one teaches the same topic, just send the teaching materials directly through e-mail and we can just discuss it. Why do we have to bother using an e-portfolio? ... We just get in touch with our peers through e-mails, phone calls, and Facebook; something more convenient than an eportfolio. Who else would bother gaining access to it? Our future schools? Our future employers? I don't know whether they have the interest to get to know what an e-portfolio is. (Student $\mathrm{H}$ )

\section{Limitations and Future Directions}

This article presented a research with only nine students so it is inappropriate to generalize the findings. Furthermore, the research study involved student teachers of English major who could not represent the views of all other student teachers of HKIEd who had not taken part in the pilot study. There are different approaches to having an in depth understanding of the value of eportfolio for FE. Firstly, we can ask student teachers to participate in a questionnaire which asks similar questions of the focus group meetings. Data collected quantitatively can be triangulated with the qualitative data that were collected in this study so that we could have a comprehensive understanding of the merits and challenges of digitising the existing FE paper-based portfolio. Secondly since the participants studied English, it is possible that they were not particularly technology savvy. The findings would be more convincing if student teachers from other programmes could be invited to participate in the e-portfolio implementation so as to enlarge the sample size and to increase diversity. Lastly, we could gather FE supervisors' views so that we could have a holistic idea of the e-portfolio pilot implementation.

On the practical side, the e-portfolio platform could be introduced to students during their first year of study, ensuring they would be familiar with its uses for different courses or purposes. Students could use the Mahara platform for different courses, such as a research course and teaching methods course, with an emphasis on developmental processes so students could showcase their development during the course of their undergraduate studies. It would be useful to have the training session on uploading artefacts after their FE to provide the personal support (Shepard \& Hannafin, 2011). It would also be necessary to have policies in place to support the innovative use of technology, not to mention to offer better support for reflection - a key factor in efficacious portfolio implementation.

\section{Conclusions}

TAM was adapted as a research framework to examine different factors that affect e-portfolio acceptance among HKIEd student teachers who used the technology to showcase their FE journeys. Comments from nine student teachers indicated that ATU had a direct relationship on BIU. Moreover, PU was the determining factor for those who did not have a strong ATU. Although we believed that this generation of students would be comfortable with technology and be able to seamlessly interact with it, our results suggested the opposite was the case (Shephard \& Hannafin, 2011). This finding is similar to other research demonstrating 
that new e-portfolio initiatives compete with other familiar means of communication for students (Evans \& Powell, 2007; Evans \& Schwen, 2006).

We are mindful that only $12 \%$ of the eligible students participated in the interviews, our findings might not generalise to the whole cohort of students. Furthermore, some students were concerned about privacy, as they were unsure who could access their e-portfolios. They were also concerned about the period with which they could access Mahara after graduation, as their job searches may be on-going for several years. Taken together, participants' opinions proved to be illuminating and valid. With their comments in mind, HKIEd should carefully consider how best to launch e-portfolio for different courses, and plan the time and resources required to educate and train teaching staff and students in a manner that would ensure the enhancement of interaction between them.

\section{References}

Abrami, P. C., \& Barret, H. (2005). Directions for research and development on electronic portfolios. Canadian Journal of Learning and Technology, 31(3).

Ajzen, I., \& Fishbein, M. (2000). Attitudes and the attitude-behavior relation: Reasoned and automatic processes. In W. Stroebe \&. M. Hewstone. (Eds.), European review of social psychology (pp. 1-33). John Wiley \& Sons.

Ayala, J. I. (2006). Electronic portfolios for whom? Educause Quarterly, 29(1), 12-13.

Bala, S. S, Mansor, W. F. A. W., Stapa, M., \& Zhkaria, M. H. (2012) Digital Portfolio and Professional Development of Language Teachers, Procedia - Social and Behavioral Sciences 66, 176- 186.

Chau, J., \& Cheng, G. (2010). Towards understanding the potential of e-portfolios for independent learning: A qualitative study. Australasian Journal of Educational Technology, 26(7), 932-950.

Chuang, H. H. (2010). Weblog-based electronic portfolios for student teachers. Education tech research development, 58, 211-227.

Davis, F. D. (1989). Perceived usefulness, perceived ease of use, and user acceptance of information technology. MIS Quarterly, 13(3), 319-340.

Davis, F. D., Bagozzi, R. P., \& Warshaw, P. R. (1989). User acceptance of computer technology: A comparison of two theoretical models. Management Science, 35, 982-1003.

Evans, M. A., \& Powell, A. (2007). Conceptual and practical issues related to the design for and sustainability of communities of practice: The case of e-portfolio use in preservice teacher training. Technology, Pedagogy and Education, 16(2), 199-214.

Evans, M. A., \& Schwen, T. M. (2006). Chasing a fault across ship and shore: Explaining knolwedge and work in context. Performance Improvement Quarterly, 19(2), 211-229.

Gaide, S. (2006). ePortfolio: Supercharge performance-based student assessment. Distance Education Report, 10(2), 14-16.

Gao, Y. (2005). Applying the Technology Acceptance Model (TAM) to educational hypermedia: A field study. Journal of Educational Multimedia and Hypermedia, 14(3), 237-247.

Goldsby, D. S., \& Fazal, M. B. (2000). Technology's answer to portfolios for teachers. Kappa Delta Pi Record, 36(3), 121-123.

Hallam, G., \& Creagh, T. (2010). ePortfolio use by university students in Australia: A review of the Australian ePortfolio Project. Higher Education Research \& Development, 29(2), 179-293.

Herner-Patnode, L., \& Lee, H.-J. (2009). A capstone experience for preservice teachers: Building a webbased portfolio. Educational Technology and Society, 12(1), 101-110.

Hussein, N. H. N. (2009). Students perspectives on the engagement of electronic portfolio as a tool in classroom instruction. Journal of Human Capital Development, 2(1), 53-64. 
Jafari, A. (2004). The "sticky" eportfolio system. Tackling challenges \& identifying attributes. EDUCAUSE Review, 39(4), 38-49.

Makinster, J. G., Barab, S., Harwood, W., \& Anderson, H. O. (2006). The effect of social context on reflective practice of preservice science teachers: Incorporating a web-supported community of teachers. The Journal of Technology and Teacher Education, 14(3), 543-579.

McKinnon, K., \& Igonor, A. (2008). Explaining elearning perceptions using the Technology Acceptance Model and the Theory of Planned Behavior. Proceedings of the World Conference on E-Learning in Corporate, Government, Healthcare, and Higher Education 2008. Chesapeake, VA: AACE.

Nov, O., \& Ye, C. (2008). Users' personality and perceived ease of use of digital libraries: The case for resistance to change. Journal of the American Society for Information Science and Technology, 59(5), 845-851.

Orland-Barak, L. (2005). Portfolios as evidence of reflective practice: What remains 'untold'. Educational Research, 47(1), 25-44.

Park, N. (2009). User acceptance of e-learning in higher education: An application of the Technology Acceptance Model. Paper presented at the Annual meeting of the International Communication Association, New York.

Shepherd, C., \& Bolliger, D. U. (2011). The effects of electronic portfolio tools on online students' perceived support and cognitive load. Internet and Higher Education, 14, 142-149.

Shepherd, C., \& Hannafin, M. (2011). Supporting preservice teacher inquiry with electronic portfolios. Journal of Technology and Teacher Education, 19(2), 189-207.

Shroff, R. H., Deneen, C., \& Ng, E. M. W. (2011). An analysis of the technology acceptance model in examining students' behavioral intention to use an electronic portfolio system. Australasian Journal of Educational Technology, 27(4), 600-618.

Strudler, N., \& Wetzel, K. (2008). Costs and benefits of electronic portfolios in teacher education: Faculty perspectives. Journal of Computing in Teacher Education, 24(4), 135-141.

Sugar, W., Crawley, F., \& Fine, B. (2004). Examining teachers' decisions to adopt new technology. Educational Technology and Society, 7(4), 201-213.

Sung, Y.-T., Chang, K. -E, Yu, W. -C, Chang, T. -H (2008). Supporting teachers' reflection and learning through structured digital teaching portfolios. Journal of Computer Assisted Learning, 25, 375-385.

Teo, T. (2009). Modelling technology acceptance in education: A study of pre-service teachers. Computers \& Education, 52(2), 302-312.

Thang, D., Lee, Y S, Zulifli (July 2012). The role of the electronic portfolio in enhancing information and communication technology and English lanuage skills: the voices of six Malaysian undergraduates. Computer assisted language learning, 25(3), 277-293.

Wright, V. H., Stallworth, B. J., \& Ray, B. (2002). Challenges of electronic portfolios: Student perceptions and experiences. Journal of Technology and Teacher Education, 10(1), 49-61.

Zhang, S. X., Olfman, L., \& Ractham, P. (2007). Designing eportfolio 2.0: Integrating and coordinating web 2.0 services with eportfolio systems for enhancing users' learning. Journal of Information Systems Education, 18, 203-214.

\section{Acknowledgement}

The authors are very thankful to students for participating and allowing the authors to cite their work and comments. Special thanks go to our colleagues Drs. Stella Kong, John Trent, Elizabeth Walker and LiXunWang for their support. 


\section{Biographies}

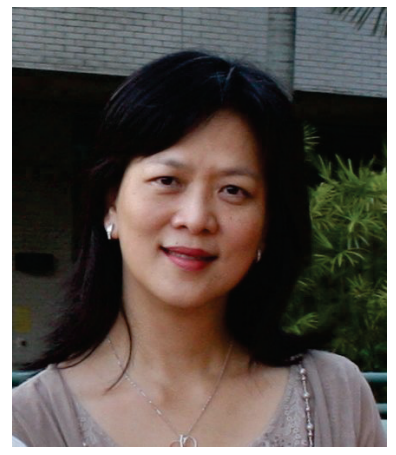

Eugenia M. W. Ng is an associate professor in the Mathematics and Information Technology Department of the Hong Kong Institute of Education. She has been a research investigator of various internal and external funded projects. She has had over ninety articles published in conference proceedings, journals, newspapers and as book chapters. Her publications have appeared in many reputable international journals such as Australasian Journal of Information Technology, Issues in Informing Science and Information Technology, Internet and Higher Education. She was the editors and co-editor for a number of referred books and journals.

Ronnie H. Shroff was an Assistant Professor at The Hong Kong Institute of Education and is working at Hong Kong Baptist University. His research focuses on the development of cognitive learning skills and motivational dispositions and how this development can be facilitated through learner-centred mediated instruction across various teaching and learning settings.

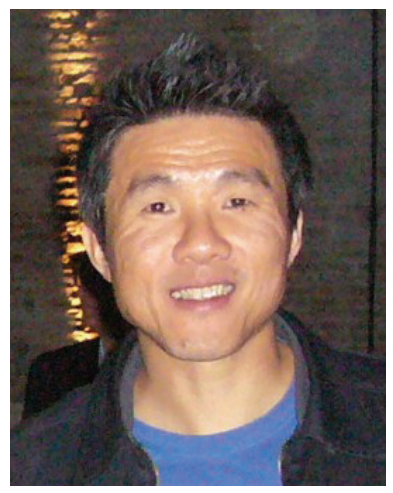

Cher Ping Lim is a Professor in the Department of Curriculum and Instruction and Director of the Centre for Learning, Teaching and Technology at the Hong Kong Institute of Education. He has published internationally in different areas of education technologies, including ICT-based learning environments in schools, teacher education and corporations 